\title{
EGU2020-8610
}

https://doi.org/10.5194/egusphere-egu2020-8610

EGU General Assembly 2020

(c) Author(s) 2020. This work is distributed under

the Creative Commons Attribution 4.0 License.

\section{A Nine-year series of daily oxygen and hydrogen isotopic composition of precipitation at Concordia station, East Antarctica}

\author{
Barbara Stenni ${ }^{1}$, Giuliano Dreossi ${ }^{2}$, Mathieu Casado ${ }^{3}$, Claudio Scarchilli ${ }^{4}$, Amaelle Landais ${ }^{5}$, \\ Massimo Del Guasta ${ }^{6}$, Paolo Grigioni ${ }^{4}$, Giampietro Casasanta ${ }^{7}$, Martin Werner ${ }^{8}$, Mauro Masiol ${ }^{1}$, \\ Alexandre Cauquoin $^{8,9}$, and Virginia Ciardini ${ }^{4}$ \\ ${ }^{1}$ Department of Environmental Sciences, Informatics and Statistics, Ca' Foscari University of Venice, Italy \\ (barbara.stenni@unive.it) \\ ${ }^{2}$ CNR-ISP, Venice, Italy \\ ${ }^{3}$ Alfred Wegener Institute Helmholtz Centre for Polar and Marine Research, Telegrafenberg A6, 14473 Potsdam, Germany \\ ${ }^{4}$ ENEA, Centro Ricerche Casaccia, Rome, Italy \\ ${ }^{5}$ Laboratoire des Sciences du Climat et de l'Environnement/IPSL, UMR 8212, CEA-CNRS-UVSQ, Gif/Yvette, France \\ ${ }^{6} \mathrm{CNR}$-INO, Sesto Fiorentino, Italy \\ ${ }^{7}$ CNR-ISAC, Rome, Italy \\ ${ }^{8}$ Alfred Wegener Institute Helmholtz Centre for Polar and Marine Research, Bussestraße 24, 27570 Bremerhaven, Germany \\ ${ }^{9}$ Institute of Industrial Science, The University of Tokyo, 5-1-5 Kashiwanoha, Kashiwa, 277-8574 Chiba, Japan
}

The atmospheric processes determining the isotopic composition of precipitation on the Antarctic plateau are yet to be fully understood, as well as the post-depositional processes altering the snow pristine isotopic signal. Improving the comprehension of these physical mechanisms is of crucial importance for interpreting the isotopic records from ice cores drilled in the low accumulation area of Antarctica, e.g., the upcoming Beyond EPICA drilling at Little Dome C.

Up to now, few records of the isotopic composition of precipitation in Antarctica are available, most of them limited in time or sampling frequency. Here we present a 9-year long $\delta^{18} \mathrm{O}$ and $\delta \mathrm{D}$ record (2008-2016) of precipitation at Concordia base, East Antarctica. The snow is collected daily on a raised platform $(1 \mathrm{~m})$, positioned in the clean area of the station; the precipitation collection is still being carried out each year by the winter over personnel.

A significant positive correlation between isotopes in precipitation and 2-m air temperature is observed at both seasonal and interannual scale; the lowest temperature and isotopic values are usually recorded during winters characterized by a strongly positive Southern Annular Mode index.

To improve the understanding of the mechanisms governing the isotopic composition of precipitation, we compare the isotopic data of Concordia samples with on-site observations, meteorological data from the Dome C AWS of the University of Wisconsin-Madison, as well as with high-resolution simulation results from the isotope-enabled atmospheric general circulation models ECHAM5-wiso and ECHAM6-wiso, nudged with the ERA-Interim and ERA5 reanalyses 
respectively.

How to cite: Stenni, B., Dreossi, G., Casado, M., Scarchilli, C., Landais, A., Del Guasta, M., Grigioni, P., Casasanta, G., Werner, M., Masiol, M., Cauquoin, A., and Ciardini, V.: A Nine-year series of daily oxygen and hydrogen isotopic composition of precipitation at Concordia station, East Antarctica, EGU General Assembly 2020, Online, 4-8 May 2020, EGU2020-8610,

https://doi.org/10.5194/egusphere-egu2020-8610, 2020 